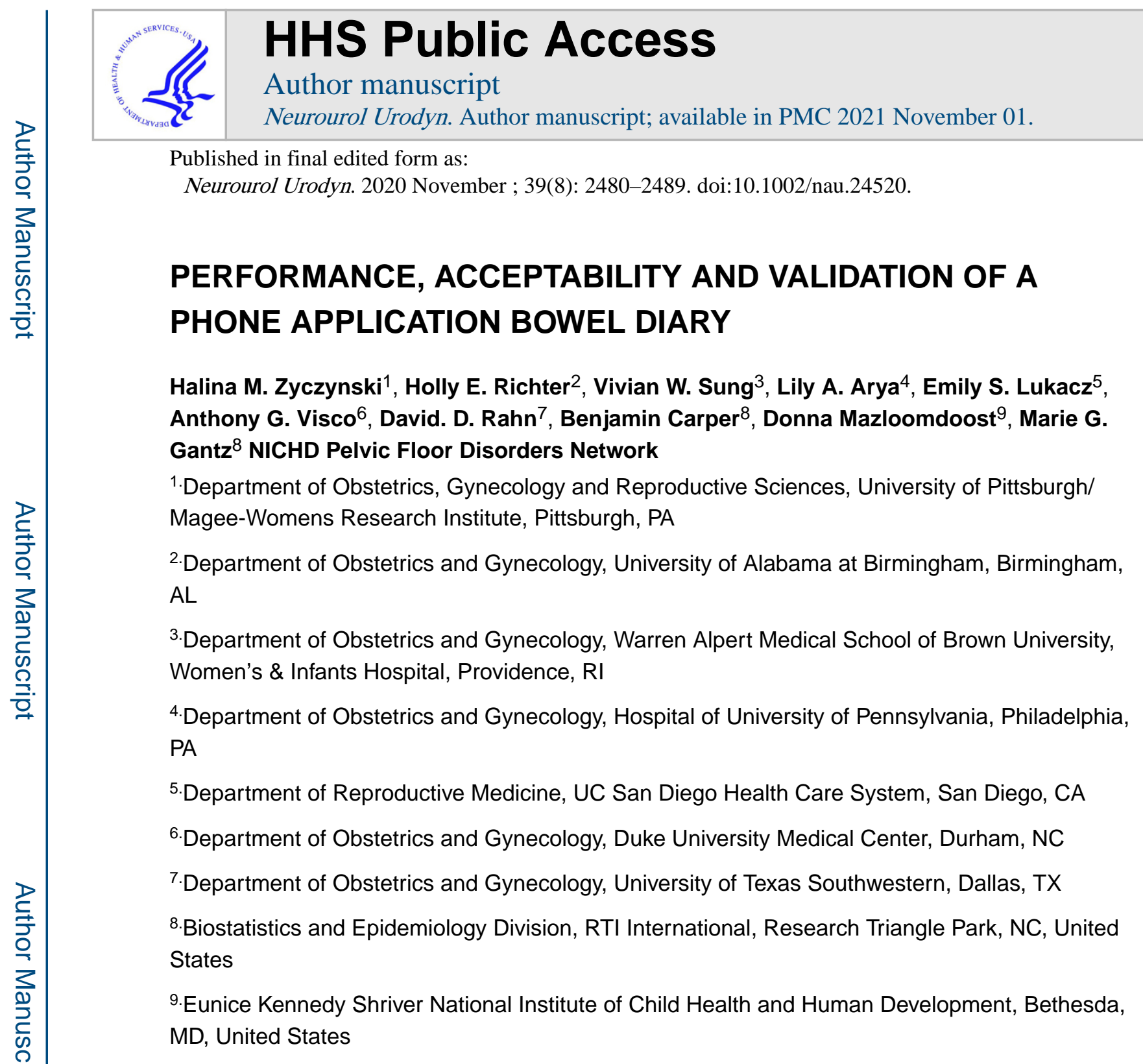

Published in final edited form as:

Neurourol Urodyn. 2020 November ; 39(8): 2480-2489. doi:10.1002/nau.24520.

\title{
PERFORMANCE, ACCEPTABILITY AND VALIDATION OF A PHONE APPLICATION BOWEL DIARY
}

\author{
Halina M. Zyczynski ${ }^{1}$, Holly E. Richter ${ }^{2}$, Vivian W. Sung ${ }^{3}$, Lily A. Arya ${ }^{4}$, Emily S. Lukacz ${ }^{5}$, \\ Anthony G. Visco ${ }^{6}$, David. D. Rahn ${ }^{7}$, Benjamin Carper $^{8}$, Donna Mazloomdoost ${ }^{9}$, Marie G. \\ Department of Obstetrics, Gynecology and Reproductive Sciences, University of Pittsburgh/ \\ $\mathrm{AL}$ \\ 3.Department of Obstetrics and Gynecology, Warren Alpert Medical School of Brown University, \\ 4.Department of Obstetrics and Gynecology, Hospital of University of Pennsylvania, Philadelphia, \\ Department of Obstetrics and Gynecology, Duke University Medical Center, Durham, NC \\ Department of Obstetrics and Gynecology, University of Texas Southwestern, Dallas, TX \\ 8. Biostatistics and Epidemiology Division, RTI International, Research Triangle Park, NC, United \\ States \\ MD, United States
}

\begin{abstract}
Aims: To assess performance, acceptability, external validity, and reliability of a phone application electronic bowel diary (PFDNBowel eDiary).

Methods: Women reporting refractory accidental bowel leakage (ABL) were enrolled in a randomized, crossover trial evaluating paper vs eDiary documentation of bowel movements (BM) and fecal incontinence episodes (FIE). Events were characterized by presence or absence of urgency and Bristol Stool Scale consistency. The eDiary entries were date/time stamped and prompted by twice-daily phone notifications. Women were randomized to complete up to 3 consecutive 14-day diaries in 2 sequences. Diary events were compared between formats using
\end{abstract}

\footnotetext{
Corresponding Author Halina M. Zyczynski, MD, Department of Obstetrics, Gynecology and Reproductive Sciences, MageeWomens Hospital, 300 Halket Street, Pittsburgh, PA 15213, hzyczynski@mail.magee.edu, Phone: 412.641.1440.

Clinical Trials. gov NCT 03278613

CIRB: Neuromodulation for Accidental Bowel Leakage: NOTABLE PRO17090006
} 
Pearson correlation. System Usability Scale (SUS) assessed eDiary usability. The eDiary testretest reliability was assessed with Intraclass Correlations (ICCs).

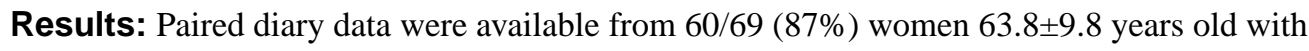
mean 13.2 BM/week and 6.5 FIE/week (nearly half with urgency). Among those providing diaries, adherence did not differ by paper or eDiary ( $93.3 \%$ vs $95.0 \%$ ). Notifications prompted $29.6 \%$ of eDiary entries, improving adherence from $70 \%$ to $95 \%$. Paper and eDiaries were moderate tostrongly correlated for BMs/week ( $r=0.61)$, urgency BMs/week ( $r=0.76)$, FIE/week ( $r=0.66)$, urgency FIE/week ( $r=0.72$ ). Test-retest reliability was good (ICC=0.81 BMs/week, 0.79 urgency BMs/week, 0.74 FIE/week, and 0.62 urgency FIE/week). Mean SUS score was high, 82.3 \pm 17.5 (range $0-100$ ) with $91.4 \%$ rating it easy to use, and $75.9 \%$ preferring the eDiary over paper.

Conclusion: The PFDNBowel eDiary correlated well with paper diary, was considered easy to use, preferred to paper diaries, had high rates of confirmed real-time diary completion that obviated staff data entry.

\section{Keywords}

Bowel ediary; Electronic bowel diary; Phone application diary; Fecal incontinence; Accidental bowel leakage

\section{Introduction}

Accidental bowel leakage (ABL) or fecal incontinence (FI) is a common condition that affects the lives of up to $20 \%$ of women in the United States. $1,2,3,4,5$ The bowel diary is widely used in the diagnosis and management of $\mathrm{ABL}$ and is also frequently used to assess key outcomes in clinical trials. ${ }^{6-7}$ Unlike subjective questionnaires, a prospective bowel diary is an objective assessment into which subjects record characteristics of bowel symptoms and frequency of incontinence episodes in real time.

Paper diaries are the most common form of bowel diary. However, these are cumbersome to carry and complete in real-time, and accuracy has long been of concern due to the potential for back-filling and front-filling of forms. ${ }^{8}$ Electronic diaries may overcome bias and enhance veracity through programming parameters for date and time stamps of events, and restrictions to retrospective data entry. Smart phone applications provide an advantage of reminder notifications to prompt data entry at designated time points. In the case of urinary incontinence, electronic diaries have demonstrated greater accuracy and reliability of micturition and incontinence frequency data compared with paper diaries. ${ }^{9-11}$ For research programs, the immediate electronic recording of participant-entered data also reduces the work and errors associated with manual data entry by research staff. ${ }^{8,10,12 .}$

Motivated by the potential advantages of improved compliance, enhanced data quality, and reduced administrative costs, the Pelvic Floor Disorders Network, a multicenter clinical trials network established by the Eunice Kennedy Shriver National Institute of Child Health and Human Development, developed a phone application electronic bowel diary (PFDN Bowel eDiary) for use in its NeurOmodulaTion for Accidental Bowel Leakage (NOTABLe) study. In this planned supplementary study of the NOTABLe trial, we assessed the performance, acceptability, test-retest reliability, and external validity of the PFDNBowel 
eDiary compared to a paper bowel diary in community dwelling women with symptoms of accidental bowel leakage.

\section{Materials and Methods}

\section{Study Design}

This study is a randomized crossover trial design comparing paper and eDiary versions of a 14-day bowel diary. Participants completed a 14-day eDiary followed by a 14-day paper diary, or vice versa, during a 28 -day run-in to the NOTABLe trial. The subset who remained eligible after the run-in and were randomized to the intervention phase completed an additional 14-day 'baseline' eDiary prior to initiating their assigned stimulation, for a total of 42 consecutive days of diary recording. (Figure 1. Study Flow Diagram, Appendix)

\section{Participants and Randomization}

Participants were recruited from women consented to the NOTABLe clinical trial: a multicenter, randomized superiority trial comparing the efficacy of percutaneous tibial neural stimulation (PTNS) versus sham treatment for ABL. The study population included women with refractory FI who failed to achieve symptom control from 2 first-line treatments: supervised pelvic muscle training (PMT) and constipating medication. A minimum score of 12 on the St Mark's questionnaire was required for enrollment and for randomization to intervention groups. ${ }^{13}$ Subjects completed a 28 -day run-in phase prior to being randomized to study treatment. During this run-in phase, participants were instructed to record FIEs in two 7-day diaries (during weeks 1 and 4) and symptom severity was compared before and after the run-in to account for potential journaling effects. The run-in phase also served to identify subjects who were unable or unwilling to complete an eDiary which was an eligibility criterion for randomization to the intervention phase.

To be eligible for this supplementary study women had to own a smartphone, be willing to install the PFDNBowel eDiary application and be willing to document 14 additional diary days during the run-in period. They were randomized in a 1:1 ratio, stratified by age $(<65$ versus $\nsucceq 65$ years of age) to complete a 14-day paper diary followed by a 14-day eDiary or vice versa. The index and supplementary studies were conducted at all sites under approval from a single IRB coordinated by the University of Pittsburgh.

\section{Phone Application Specification}

The PFDNBowel eDiary application for Android (version 5.0 or higher) and iOS (version 8 or higher) operating systems captures 4 elements: the time of event entry (automatic date/ time stamp), event type (bowel movement (BM) without leakage, BM with leakage, or leakage only), stool consistency (Bristol Stool Scale), and presence of urgency. ${ }^{14}$ (Figure 2) Urgency was defined as the sudden, compelling desire to defecate that is difficult to defer. ${ }^{15}$ The eDiary generated twice-daily local notifications at pre-specified times selected by participants. At the time of each reminder notification, the app displayed a summary of recorded events since the previous notification. Women could enter additional events and were required to confirm the accuracy of the aggregate data for that period. Events entered within an hour of the notification were assumed to have occurred in the timeframe leading 
up to the notification. Data entries were automatically uploaded to the electronic data capture (EDC) system from the phones after each entry. The app does not store personal identifying information, or generate summary metrics or graphs that might be useful to individuals tracking their own events. A video demonstrating features and data entry into the eDiary can be found at https://pfdnetwork.azurewebsites.net/videos/ediary.mp4

\section{Study Procedures}

After consent, staff assisted participants with downloading the eDiary application to their smartphones and instructed them on data entry into both the paper diary and eDiary. Staff reviewed the expectation for daily "record-as-you-go" entry-keeping. Participants were required to complete both a 14-day paper diary and a 14-day eDiary recording characteristics of each episode: bowel movement, leakage, or both. Participants could record the absence of bowel movements on that day. At the end of the two diary periods, participants attended a study visit during which staff reviewed the paper diaries for clarity and summarized the events on a Paper diary data abstraction form (Figure 3, Appendix) before keying each individual paper diary entry into the EDC system. At that visit, participants also completed the System Usability Scale (SUS) on a tablet, to provide feedback on ease of use and their preference for diary formats. ${ }^{16}$

\section{Study Outcomes}

Paper and eDiary entries were summarized separately. Summary metrics for each 14-day diary included the number of days per week with diary entries (confirmed absence of bowel movement for a given day was considered an entry), number of days with entries during each week, fecal incontinence episodes (FIEs) per week, percentage of FIEs with urgency, BMs per week, and percentage of BMs with urgency. Bristol Stool scale type was summarized as percent of total events recorded as each stool type (1 through 7).

Adherence to diary completion was defined as (a) $\geq 5$ days during the first week, (b) $\geq 10$ of 14 days, and (c) $\geq 3$ consecutive days per week for both weeks. Overall adherence (i.e., a complete diary) was defined as satisfying both $b$ and $c$. The impact of morning and evening reminder notifications on eDiary completion was assessed by comparing the number of eDiary entries that occurred within an hour of each notification with the number submitted outside of that time.

The SUS is a validated, 10-item questionnaire developed to differentiate between usable and unusable electronic products and services including hardware, software, mobile devices, websites, and applications. Respondents select from five Likert-type responses (Strongly Agree to Strongly Disagree) to statements such as: "I found the system unnecessarily complex"; "I felt very confident using the system"; "I think that I would like to use this system compared to a written diary to measure my bowel habits in a clinical study" (Table 1). The SUS is scored 0-100, higher being better, and is reliable in small sample sizes. ${ }^{16}$ 


\section{Sample Size, Power and Statistical Analysis}

A sample size of 60 participants was selected to provide a minimum of $80 \%$ power to detect a difference from zero in correlations of $r=0.4$ or greater between paper and eDiary with an alpha of 0.05 .

Demographic and clinical characteristics were compared between diary order groups (eDiary-paper vs paper-eDiary) using Fisher's exact tests and unadjusted general linear models. Diary metrics were summarized using means and standard deviations. Consistency of these measures between diary formats was assessed using Pearson correlations to evaluate external validity of the eDiary, and Bland-Altman Plots. Adherence measures were compared using Chi-square tests and Pearson correlations. Mean SUS scores for the phone app were compared between diary order groups using a t-test. For individuals who were randomized to the intervention phase of NOTABLe and completed an additional eDiary, diary metrics were compared between eDiaries using Pearson correlation, and Chi-square tests, and the test-retest reliability of the eDiary was assessed using intraclass correlation.

\section{Results}

eDiary and paper diary data were provided by $60 / 69(87 \%)$ women whose mean (SD) age was 63.8 (9.8) years. Overall, $78.3 \%$ of study participants were white, $10 \%$ were black, $66.7 \%$ had some college education, mean BMI was $29.7 \mathrm{~kg} / \mathrm{m}^{2}$, and there were no differences in clinical and demographic variables between groups.(Table 2) The eDiary application was compatible with 65/69 (94.2\%) of smartphones. All electronic data entries were successfully uploaded to the designated server of the EDC system. As a group, subjects reported a mean (SD) of 13.2 (6.1) BM/week and 6.5 (5.4) FIE/week with 47\% characterized by urgency. Adherence to diary completion among those providing paired diaries did not differ between eDiary and paper (95.0\% versus $93.3 \%, \mathrm{p}=0.64)$. Women in the oldest tertile ( $>69$ years) were as likely to complete eDiaries as the youngest tertile ( $\$ 62$ years), $94.4 \%$ vs $95.7 \%$. There was weak correlation between the diary formats in the number of days per week with entries: mean (SD) 6.6 (0.6) vs 6.9 (0.3) days, $r=0.19$; and in the number of consecutive days per week with entries: 6.3 (1.1) vs $6.9(0.4), r=0.07$, for eDiary versus paper diary respectively (Table 3 ). There was moderate to strong correlation between diary formats for measures of FIE per week ( $r=0.66)$, FIE with urgency $(r=0.72)$, BMs per week ( $r=0.61)$, BMs per week with urgency $(r=0.76)$ and the percentage of BMs of each Bristol Stool Scale type ( $r=0.56-0.80)$. No obvious bias was observed from the BlandAltman plots of FIEs/week and BMs/week from both diary formats.

At the end of the run-in phase, 53 participants advanced to the intervention phase of the NOTABLe trial. Prior to randomization, they provided a 14-day baseline eDiary (in weeks 5-6), that was used as a comparator for reproducibility analyses. We found good correlation in the mean number of days with recorded events per week on the eDiary during weeks 1-4 versus weeks 5-6 ( $r=0.63)$ (Table 3$)$. There was also good to very good reproducibility of data on FIE per week $(r=0.76)$, FIE per week with urgency $(r=0.51)$, BMs per week $(r=0.84)$, BM with urgency $(r=0.66)$. While the strength of association for the Bristol Stool Scale measures varied by type of stool consistency, most of the categories showed moderate correlation between the two eDiaries. (Table 3) 
Daily recording in the eDiary was moderately consistent across the 2 weeks for both eDiaries with a mean of 6.7 (0.8) days recorded on days 1-7 and $6.6(0.8)$ days on days 8-14 $(r=0.28)$ for the first eDiary and a mean of 6.3 (1.0) days recorded on days 1-7 and $6.4(1.0)$ days on days 8-14 $r=0.55$ ) for the second eDiary. For the run-in eDiary, participants demonstrated high adherence: $95 \%$ of eDiaries had entries on $\geq 5$ of 7 days and $98.3 \%$ had entries on $\geq 10$ of 14 days. For the eDiary in weeks 5-6, participants also demonstrated high adherence: $92.5 \%$ of eDiaries had entries on $\geq 5$ of 7 days and $90.6 \%$ had entries on $\geq 10$ of 14 days. When comparing adherence between the eDiaries, there was a slight, but statistically significant, decrease in the proportion of participants who provided a complete 14-day diary between the run-in eDiary and the eDiary in weeks 5-6 (95\% versus 90.6\%, $\mathrm{p}=0.05$ ) (Table 3). Responses to twice daily notifications accounted for $29.6 \%$ of all eDiary entries and improved adherence to run-in diary completion from $70 \%$ to $95 \%$.

Comparison of metrics from the first and second eDiaries found good (moderate) test-retest reliability as measured by Intraclass Correlation Coefficients (ICC): (BMs/week $=0.81$; urgency BMs/week = 0.79, FIE/week = 0.74, urgency FIE/week = 0.62) $($ Table 4).

The SUS scores were available from 58 participants with mean SUS Score of 82.3 (17.5) (Table 1). The assigned sequence of diary formats had no impact on participants' overall SUS score with the mean score of 83.2 (19.5) in the group completing the eDiary first and 81.5 (15.6) in the group completing the paper diary first, $(\mathrm{p}=0.71)$. Most participants, $75.9 \%$ (44/58), agreed or strongly agreed that they preferred to use the eDiary compared to the paper diary to record bowel events. An exploratory analysis of clinical and demographic characteristics found none that were associated with a preference for the eDiary format (agree/strongly agree versus neutral/disagree/strongly disagree). Additionally, women with higher frequency of bowel events (>14 bowel movements/week) were as likely to prefer the eDiary format $(75.0 \%(15 / 20))$ compared to women with less frequent bowel events $(76.3 \%$ $(29 / 38))$.

\section{Discussion}

The goal of this study was to assess the performance, acceptability, and test-retest reliability of a novel phone app electronic bowel diary compared to a conventional paper bowel diary. We anticipated that the convenience and accessibility of the PFDNBowel eDiary would result in superior event documentation and adherence. Interestingly, in this study we found that adherence did not differ by diary type. We attribute this to the highly motivated study population who were aware that their ability to provide complete diaries was an eligibility criterion for intervention in the NOTABLe trial. It is therefore not surprising that we found no significant differences between the paper and eDiary formats in recorded bowel metric data and that the eDiary had good test-retest reliability. It is further reassuring that older women were as likely as younger counterparts to provide complete eDiaries and that, overall, users overwhelming preferred to document into the eDiary over the paper diary.

In a randomized controlled trial comparing paper and electronic diaries for chronic pain, Stone et al reported high rates of non-compliance among participants assigned to the paper diary group. An embedded photo sensor microchip in the paper dairy recorded every time 
the diary was opened to make an entry. Though the paper diaries contained entries at the scheduled assessment $90 \%$ of the time, the actual adherence to data entry was only $11 \%$ to $20 \%$ (based upon the 15-45-minute response window). The investigators determined the entries were "back-filled" on $32 \%$ of the study days when the binder was never opened and forward-filled most often in the 3 to 4 days prior to a study visit. These outcomes were in stark contrast to $94 \%$ verified compliance amongst those randomized to the electronic diary.

${ }^{8}$ In the current study, bowel metrics were comparable using both diary types, although it could not be determined whether there was back or forward-filling of the paper diary as there was no electronic or remote assessment of real-time documentation. However, the date/ time stamp of events in the PFDNBowel eDiary substantially reduced concerns for the veracity of data.

Smartphones are generally accessible to owners throughout the day and provide a convenient means of collecting symptom data in real time, which is important to the validity of the research data collection. We attribute the absence of demonstrable "diary fatigue" throughout the 42 consecutive day recording period to the link between the PFDNBowel eDiary and the ubiquitous smartphone. A 2015 survey by the Pew Research Center reported that $60 \%$ American adults have a smartphone with only those age 65 and older $(30 \%)$ and those who did not complete a high school education (41\%) falling below majority ownership. ${ }^{18}$ In a recent survey of 200 women with pelvic floor disorders, $92 \%$ women overall and $75 \%$ women age 65 years and older owned a smartphone. ${ }^{19}$ In this study, though younger women were more likely than older women to use technology to track healthrelated information, the utilization of smartphone "apps" for health-related reasons was high across all age groups. In fact, it has been noted that older adults have positive attitudes about using technology for health care with the perception of a benefit and ease of use as influential factors for older adults to use mHealth (mobile health) apps. ${ }^{20-21}$ In a separate study, Nippita et al reported that $50 \%$ of challenges of using an electronic diary were addressed with trouble shooting and education. ${ }^{12}$ In the current study, all participants were smartphone owners and research staff were instructed to provide participants advice and technical support to the extent needed for successful use of the PFDNBowel eDiary.

Limitations of this study include that participants were exclusively women who owned smartphones. Their adherence to diary completion was incentivized by their continued eligibility for the intervention phase of the index trial. It is possible use of a similar eDiary in other ABL studies without this eligibility criterion may collect less robust datasets. The high level of engagement and adherence to event recording was both an advantage and disadvantage to this diary validation study as the participants provided robust datasets for the analyses regardless of diary format. Another potential limitation was the investigators' priority to simplify event recording by not including daily surveillance of pad use or constipating medications. These adaptations practiced by women with ABL were captured in questionnaires. We did not collect self-reported information on the frequency of retrospective data recording on paper diaries therefore we cannot compare the frequency and reliability of such documentation between diary formats.

This study contributes supportive evidence for the value of reminder notifications for future diary app developers. The strengths of the study include a robust assessment of test-retest 
reliability, and of external validity compared to the conventional paper diary for objective measurement of FIEs.

\section{Conclusions}

The frequency and characteristics of bowel events collected by the PFDNBowel eDiary correlated well with the paper diary. Participants of all ages considered it easy to use and preferred it over the paper diary. The high completion rates in real-time obviated the efforts of data entry by research staff. Use in other clinical research settings needs to be assessed.

\section{Acknowledgements}

NOTABLe eDiary Acknowledgements

University of Alabama at Birmingham: Danielle Aaron, Kathy Carter, David Ellington, Ryanne Johnson, Alayne Markland, Jeannine McCormick, Isuzu Meyer, R. Edward Varner, Robin Willingham

Brown University Women \& Infants Hospital of Rhode Island: Cassandra Carberry, B. Star Hampton, Nicole
Korbly, Ann Schantz Meers, Deborah L. Myers, Charles R. Rardin, Kyle Wohlrab, Sarashwathy K. Veera, Elizabeth-Ann R. Viscione

University of California at San Diego: Michael Albo, Marianna Alperin, Stephanie Armstrong, Laura Aughinbaugh, Linda Brubaker, Tatiana Catanzarite, Kyle Herrala, Stephanie Micucci, Charles Nager, Dulce Rodriguez-Ponciano, Sandra Roman,

Duke University Medical Center: Cindy L. Amundsen, Matthew D. Barber, Yasmeen Bruton, Nortorious ColemanTaylor, Cassandra Hanson, John E. Jelovsek, Amy Kavanagh, Amie Kawasaki, Shantae McLean, Tracey O'Dowd, John Owens, Nazema Y. Siddiqui, Katelyn C. Smith, Alison C. Weidner

University of Pennsylvania: Uduak Andy, Yelizaveta Borodyanskaya, Lorraine Flick, Heidi Harvie, Zandra Kennedy

University of Pittsburgh Magee-Womens Hospital: Mary Ackenbom, Lindsey Baranski, Michael Bonidie, Megan Bradley, Pamela Fairchild, Judy Gruss, Beth Klump, Lauren Kunkle, Jacqueline Noel, Pamela Moalli, Margaret Rajkovic

University of Texas Southwestern: Shanna Atnip, Sunil Balgobin, Juanita Bonilla, Agnes Burris, Marlene Corton, Maria Florian-Rodriguez, Christy Hegan, Priscilla Reynolds, Joseph Schaffer, Alison Schmitt, Clifford Wai

RTI International: Andrew Burd, Kate Burdekin, Kendra Glass, Michael Ham, Pooja Iyer, Peter Robbins, Amanda Shaffer, Taylor Swankie, Sonia Thomas, Kevin Wilson, Dennis Wallace

Funding:

Eunice Kennedy Shriver National Institute of Child Health and Human Development, and NIH Office of Research on Women's Health, Grant Numbers: 2UG1 HD069006, 2UG1 HD041261, 2UG1 HD069013, 2 UG1 HD069010, 2 UG1 HD054214, 2 UG1 HD041267, 2 UG1 HD054241, 2 U24 HD069031 
APPENDIX

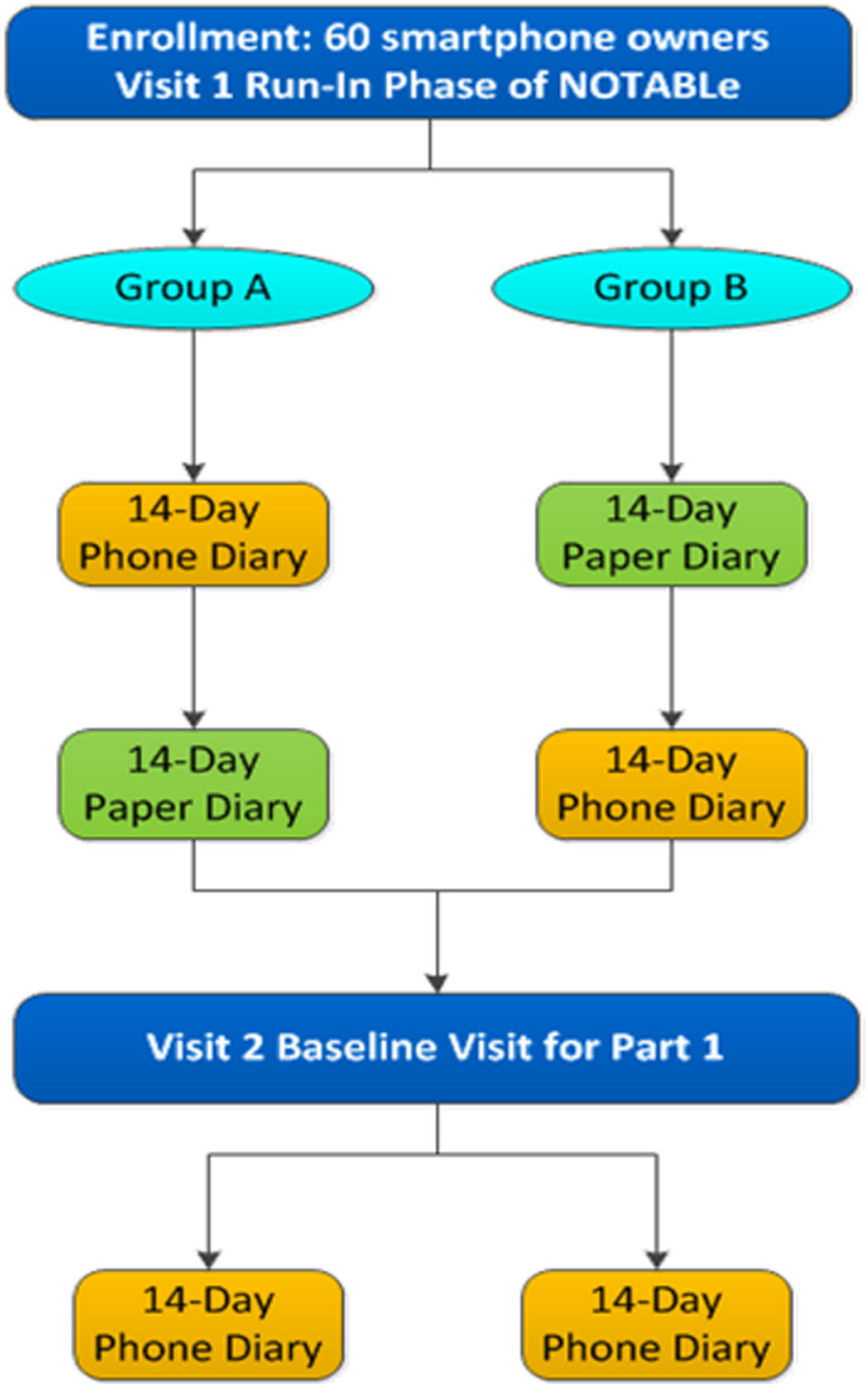

Figure 1.

Study Flow Diagram 


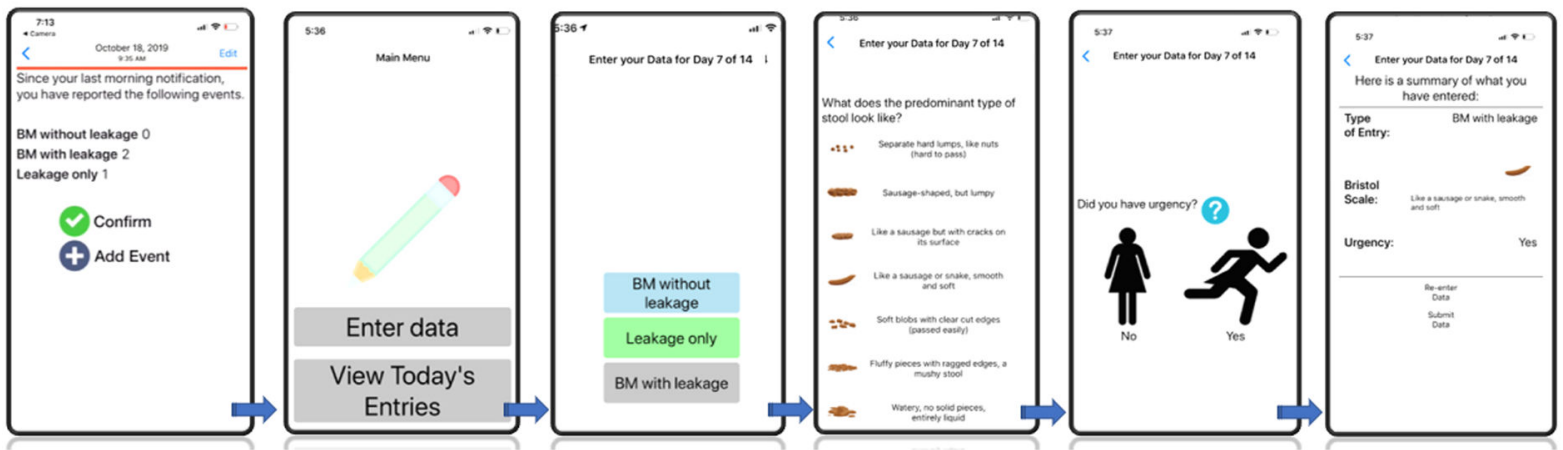

Figure 2.

PFDN Bowel eDiary phone screen shots

The coordinator will abstract the following data from the participant's paper bowel diary entries. During the Run-In, participants not participating in the Supplementary Study will complete 7-day diaries and only summary data will be abstracted for Medidata entry.

A1. Did the parficipant retum a completed bowel diary with entries $\alpha n \geq 10$ days (Week 1 and Week 4 combined)? $\square$ Yes $\square$ No

Section B: Diary Week 1: Bowel Leakage and Associated Sensation

B1. Are there $\geq 3$ consecutive days of diary entries in the first 7 days (Week 1 dary)? $\square$ Yes $\square$ No

B2. Start date of Week 1 bowel diary.

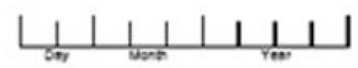

\begin{tabular}{|c|c|c|c|c|c|c|c|}
\hline Week 1 Diary & Day 1 & Day 2 & Day 3 & Day 4 & Day 5 & Day 6 & Day 7 \\
\hline \multicolumn{8}{|l|}{ B3. Number of bowel movements without leakage } \\
\hline a. Of these, how many were associated with "urgency"? & & & & & & & \\
\hline \multicolumn{8}{|l|}{ B4. Number of leakage only } \\
\hline a. Of these, how many were associated with "urgency"? & & & & & & & \\
\hline \multicolumn{8}{|l|}{ B5. Number of bowel movements with leakage } \\
\hline a. Of these, how many were associated with "urgency"? & & & & & & & \\
\hline
\end{tabular}

Section C: Diary Week 4: Bowel Leakage and Associated Sensation

C1. Are there $\geq 3$ consecutive days of diary entries in the second 7 days (Week 4 diary)? $\square$ Yes $\square$ No

C2 Start date of Week 4 bowel

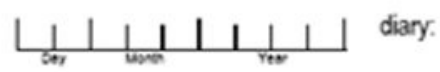

\begin{tabular}{|l|l|l|l|l|l|l|l|}
\hline Week 4 Diary & Day 1 & Day 2 & Day 3 & Day 4 & Day 5 & Day 6 & Day 7 \\
\hline C3. Number of bowel movements without leakage & & & & & & & \\
\hline a. Of these, how many were associated with urgency? & & & & & & & \\
\hline C4. Number of leakage only & & & & & & & \\
\hline a. Of these, how many were associated with urgency? & & & & & & & \\
\hline C5. Number of bowel movements with leakage & & & & & & & \\
\hline a. Of these, how many were associated with "urgency? & & & & & & & \\
\hline
\end{tabular}

Final V2.0 02Nov2017

Page 1 of 1

Figure 3.

Paper diary data abstraction form 


\section{References}

1. Nelson R, Norton N, Cautley E, Furner S. Community-based prevalence of anal incontinence. JAMA. 1995;274:559-61. [PubMed: 7629985]

2. Bharucha AE, Zinsmeister AR, Locke GR, Seide BM, McKeon K, Schleck CD, et al. Prevalence and burden of fecal incontinence: a population-based study in women. Gastroenterology. 2005;129:42-9. [PubMed: 16012933]

3. Melville JL, Fan MY, Newton K, Fenner D. Fecal incontinence in US women: a population-based study. Am J Obstet Gynecol. 2005;193:2071-6. [PubMed: 16325618]

4. Brown HW, Wexner SD, Segall MM, Brezoczky KL, Lukacz ES. Accidental bowel leakage in the mature women's health study: prevalence and predictors. Int J Clin Pract. 2012;66:1101-8. [PubMed: 23067034]

5. Dey AN. Characteristics of elderly nursing home residents: data from the 1995 National Nursing Home Survey. Adv Data. 1997;289:1-8.

6. Rao SS, American College of Gastroenterology Practice Parameters Committee. Diagnosis and management of fecal incontinence. Am J Gastroenterol. 2004;99:1585-1604 [PubMed: 15307881]

7. Baxter NN, Rothenberger DA, Lowry AC. Measuring fecal incontinence. Dis Colon Rectum. 2003;46:1591-1605. [PubMed: 14668583]

8. Stone A, Shiffman S, Schwartz J, Broderick J, Hufford M. Patient compliance with paper and electronic diaries. Controlled Clinical Trials. 2003;24:182-99. [PubMed: 12689739]

9. Mateu Arrom L, Peri Cusi L, López-Fando L, Franco de Castro A, Jiménez Cidre MÁ, Alcaraz A. Validation of a 3-day electronic bladder diary as an app for smart-phone. Neurourol Urodyn. 2019;38:764-769. [PubMed: 30620092]

10. Quinn P, Goka J, Richardson H. Assessment of an electronic daily diary in patients with overactive bladder. BJU Int. 2003;91:647. [PubMed: 12699477]

11. Abrams P, Paty J, Martina R, Newgreen DT, van Maanen R, Paireddy A, Kuipers-deGroot T, Ridder A. Electronic bladder diaries of differing duration versus a paper diary for data collection in overactive bladder. Neurourol Urodyn. 2016;35:743-9. [PubMed: 26174907]

12. Nippita S, Oviedo JD, Velasco MG, Westhoff CL, Davis AR, Castaño PM. A randomized controlled trial of daily text messages versus monthly paper diaries to collect bleeding data after intrauterine device insertion. Contraception. 2015;92:578-84. [PubMed: 26363433]

13. Vaizey CJ, Carapeti E, Cahill JA, Kamm MA. Prospective comparison of faecal incontinence grading systems. Gut . 1999;44:77-80. [PubMed: 9862829]

14. Lewis SJ, Heaton KW. Stool form scale as a useful guide to intestinal transit time. Scand J Gastroenterol. 1997;32:920-4. [PubMed: 9299672]

15. Sultan AH, Monga A, Lee J, Emmanuel A, Norton C, Santoro G, Hull T, Berghmans B, Brody S, Haylen BT. An International Urogynecological Association (IUGA) / International Continence Society (ICS) Joint Report on the Terminology for Anorectal Dysfunction in Women. Int Urogynaecol 2017;28:5-31.

16. Bangor A, Kortum P, Miller J. The system usability scale (SUS): An empirical evaluation. Int J Hum Comput Interact. 2008;24:574-94.

17. Hodge B. The use of symptom diaries in outpatient care. Fam Prac Manag. 2013;20:24-8.

18. Anderson M. Technology Device Ownership: 2015 Pew Research Center https:// www.pewresearch.org/internet/2015/10/29/technology-device-ownership-2015/Accessed 02-15-2020.

19. Lee DD, Arya LA, Andy UU, Sammel MD, Harvie HS. Willingness of Women with Pelvic Floor Disorders to Use Mobile Technology to Communicate with Their Health Care Providers. Female Pelvic Med Reconstr Surg. 2019;25:134-8. [PubMed: 30807415]

20. Anderson G. Technology use and attitudes among mid-life and older Americans: AARP; 2017 [Available from: https://www.aarp.org/content/dam/aarp/research/surveys_statistics/technology/ info-2018/atom-nov-2017-tech-module.doi.10.26419\%252Fres.00210.001.pdf 
21. Mitzner TL, Boron JB, Fausset CB, Adams AE, Charness N, Czaja SJ, et al. Older adults talk technology: Technology usage and attitudes. Computers in Human Behavior. 2010;26:1710-21. [PubMed: 20967133] 
Table 1.

System Usability Summary results for PFDN Bowel eDiary

\begin{tabular}{|c|c|}
\hline System Usability Scale & n $(\%) \underset{(N=58)}{\text { or Mean }}(\mathrm{SD})$ \\
\hline I think that I would like to use this system compared to a written diary to measure my bowel habits in a clinical study. & $44(75.9 \%)$ \\
\hline I found the system unnecessarily complex. & $7(12.0 \%)$ \\
\hline I thought the system was easy to use. & $53(91.4 \%)$ \\
\hline I think that I would need the support of a technical person to be able to use this system. & $2(3.5 \%)$ \\
\hline I found the various functions in this system were well integrated. & $42(72.4 \%)$ \\
\hline I thought there was too much inconsistency in this system. & $3(5.2 \%)$ \\
\hline I would imagine that most people would learn to use this system very quickly. & $53(91.4 \%)$ \\
\hline I found the system very cumbersome to use. & $2(3.5 \%)$ \\
\hline I felt very confident using the system. & $51(87.9 \%)$ \\
\hline I needed to learn a lot of things before I could get going with this system. & $8(13.8 \%)$ \\
\hline SUS Score, mean(SD) & $82.3(17.5)$ \\
\hline
\end{tabular}


Table 2.

Demographic and Clinical Characteristics

\begin{tabular}{|c|c|c|c|}
\hline \multirow[b]{2}{*}{ Participant characteristic } & \multicolumn{2}{|c|}{ Diary format sequence (14-day each) } & \multirow[b]{2}{*}{$\begin{array}{l}\text { Total } \\
\mathrm{N}=60\end{array}$} \\
\hline & $\begin{array}{c}\text { eDiary-Paper } \\
\mathbf{N}=\mathbf{2 9}\end{array}$ & $\begin{array}{c}\text { Paper-eDiary } \\
\text { N=31 }\end{array}$ & \\
\hline Age, mean (SD), (years) & $64.3(10.6)$ & $63.3(9.2)$ & $63.8(9.8)$ \\
\hline$\$ 62$ years, $n$, mean $(\mathrm{SD})$ & $\mathrm{n}=11,53.6(7.5)$ & $\mathrm{n}=12,54.1(7.0)$ & $\mathrm{n}=23,53.9(7.1)$ \\
\hline 63-69 years, n, mean (SD) & $\mathrm{n}=9,66.2(2.3)$ & $\mathrm{n}=10,65.8(2.4)$ & $\mathrm{n}=19,66.0(2.3)$ \\
\hline$>69$ years, $\mathrm{n}$, mean $(\mathrm{SD})$ & $\mathrm{n}=9,75.3(4.6)$ & $\mathrm{n}=9,72.8(2.5)$ & $\mathrm{n}=18,74.1(3.8)$ \\
\hline \multicolumn{4}{|l|}{ Race, n (\%) } \\
\hline Black & $3(10.3)$ & $3(9.7)$ & $6(10.0)$ \\
\hline White & $22(75.9)$ & $25(80.6)$ & $47(78.3)$ \\
\hline Other & $3(10.3)$ & $2(6.4)$ & $5(8.3)$ \\
\hline Unknown/Not Reported & $1(3.4)$ & $1(3.2)$ & $2(3.3)$ \\
\hline \multicolumn{4}{|l|}{ Ethnicity, n(\%) } \\
\hline Not Hispanic/Latina & $28(96.6)$ & $28(90.3)$ & $56(93.3)$ \\
\hline \multicolumn{4}{|l|}{ Marital status n (\%) } \\
\hline Single, never married & $2(6.9)$ & $4(12.9)$ & $6(10.0)$ \\
\hline Married/Living with partner & $21(72.4)$ & $14(45.2)$ & $35(58.3)$ \\
\hline Divorced/Separated & $4(13.8)$ & $10(32.3)$ & $14(23.3)$ \\
\hline \multicolumn{4}{|l|}{ Education, n (\%) } \\
\hline High School/GED & $10(34.5)$ & $10(32.3)$ & $20(33.3)$ \\
\hline Some College & $19(65.5)$ & $21(67.7)$ & $40(66.7)$ \\
\hline \multicolumn{4}{|l|}{ Insurance, $\mathrm{n}(\%)$} \\
\hline Private/HMO & $20(69.0)$ & $20(64.5)$ & $40(66.7)$ \\
\hline Medicaid/Medicare & $13(44.8)$ & $16(51.6)$ & $29(48.3)$ \\
\hline BMI, mean (SD) & $28.3(5.4)$ & $31.0(5.9)$ & $29.7(5.8)$ \\
\hline Current smoker, n (\%) & $5(17.2)$ & $2(6.5)$ & $7(11.7)$ \\
\hline Vaginal deliveries, median [IQR] & $2[1,3]$ & $2[2,3]$ & $2[1,3]$ \\
\hline Prior anal/rectal surgery, n (\%) & $7(24.1)$ & $4(12.9)$ & $11(18.3)$ \\
\hline Prior pelvic organ prolapse surgery, n (\%) & $6(20.7)$ & $11(35.5)$ & $17(28.3)$ \\
\hline Hysterectomy, n (\%) & $14(48.3)$ & $16(51.6)$ & $30(50.0)$ \\
\hline
\end{tabular}


Table 3.

Comparison of electronic and paper bowel diary summary metrics

\begin{tabular}{|c|c|c|c|c|c|c|}
\hline \multirow[b]{2}{*}{ Diary Measure } & \multirow[b]{2}{*}{ Category } & \multicolumn{2}{|c|}{ Weeks 1-4 } & \multicolumn{3}{|c|}{ Weeks 5-6 } \\
\hline & & $\begin{array}{l}\text { eDiary } \\
(\mathbf{N}=60)\end{array}$ & $\begin{array}{l}\text { Paper Diary } \\
\quad(\mathrm{N}=56)^{d}\end{array}$ & $\begin{array}{c}\text { Pearson } \\
\text { Correlation }^{a}\end{array}$ & $\begin{array}{l}\text { eDiary } \\
(\mathrm{N}=53)\end{array}$ & $\begin{array}{c}\text { Pearson } \\
\text { Correlation } b\end{array}$ \\
\hline \multicolumn{7}{|l|}{ Completion Measures } \\
\hline Days per week, mean (SD) & & $6.6(0.6)$ & $6.9(0.3)$ & 0.19 & $6.3(0.9)$ & 0.63 \\
\hline Consecutive days per week, mean (SD) & & $6.3(1.1)$ & $6.9(0.4)$ & 0.07 & $5.9(1.4)$ & 0.63 \\
\hline Mean days during 1 st 7 days & & $6.7(0.8)$ & $7.0(0.1)$ & $<.01$ & $6.3(1.0)$ & 0.44 \\
\hline Mean days during 2 nd 7 days & & $6.6(0.8)$ & $6.8(0.5)$ & 0.04 & $6.4(1.0)$ & 0.42 \\
\hline \multicolumn{7}{|l|}{ Event Measures } \\
\hline FIEs per week, mean (SD) & & $6.2(5.3)$ & $7.8(7.7)$ & 0.66 & $5.8(5.0)$ & 0.76 \\
\hline FIEs with urgency, $\%$ & & 43.9 & 54.4 & 0.72 & 43.9 & 0.51 \\
\hline BMs per week, mean (SD) & & $12.9(6.7)$ & $14.2(8.5)$ & 0.61 & $12.6(5.5)$ & 0.84 \\
\hline BMs with urgency, $\%$ & & 47.4 & 49.0 & 0.76 & 51.7 & 0.66 \\
\hline \multirow{8}{*}{ Bristol Stool Scale ${ }^{e}, \%$} & Type 1 & 4.8 & 5.3 & 0.80 & 8.0 & 0.38 \\
\hline & Type 2 & 9.5 & 5.3 & 0.64 & 8.4 & 0.44 \\
\hline & Type 3 & 12.1 & 12.3 & 0.56 & 16.3 & 0.54 \\
\hline & Type 4 & 29.0 & 26.6 & 0.68 & 26.7 & 0.70 \\
\hline & Type 5 & 21.9 & 25.0 & 0.64 & 21.9 & 0.76 \\
\hline & Type 6 & 17.1 & 18.0 & 0.68 & 15.4 & 0.54 \\
\hline & Type 7 & 5.6 & 6.1 & 0.74 & 3.2 & 0.62 \\
\hline & & & & P-value ${ }^{a}$ & & P-value $b$ \\
\hline \multicolumn{7}{|l|}{ Adherence Measures } \\
\hline Adherence rate (completed diaries) ${ }^{c}, \mathrm{n}(\%)$ & & $57(95.0)$ & $56(93.3)$ & $\mathrm{p}=0.64$ & $48(90.6)$ & $\mathrm{p}=0.05$ \\
\hline At least 5 of 7 days recorded, n (\%) & & $57(95.0)$ & $56(93.3)$ & $\mathrm{p}=0.64$ & $48(90.6)$ & $\mathrm{p}=0.05$ \\
\hline At least 10 of 14 days recorded, $n(\%)$ & & $59(98.3)$ & $56(93.3)$ & $\mathrm{p}=0.79$ & $49(92.5)$ & $\mathrm{p}=0.77$ \\
\hline At least 3 consecutive days per week, $\mathrm{n}(\%)$ & & $58(96.7)$ & $56(93.3)$ & $\mathrm{p}=0.70$ & $49(92.5)$ & $\mathrm{p}<.0 .01$ \\
\hline
\end{tabular}

${ }^{a}$ Comparison of 14-day e-diary and paper diary completed during weeks 1-4. Pearson correlations are reported for continuous measures and Chisquare test p-values are reported for categorical measures.

${ }^{b}$ Comparison of 14-day e-diaries completed during weeks 1-4 and weeks 5-6. Pearson correlations are reported for continuous measures and Chisquare test p-values are reported for categorical measures.

${ }^{c}$ Adherence rate defined as data recorded on at least 10 of 14 days and on at least 3 consecutive days per week for 2 weeks. Calculated with $\mathrm{N}=60$ for both eDiary and paper

${ }^{d}$ Four participants did not return a paper diary and are not included in the calculation of numbers of days and/events but are included in the adherence percentage calculations

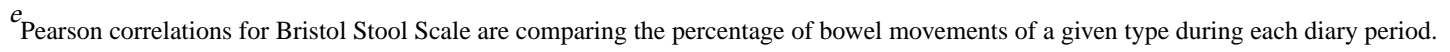


Table 4.

Intraclass correlations for comparisons between eDiaries

\begin{tabular}{lc}
\hline & $\begin{array}{l}\text { Intraclass } \\
\text { Correlation }\end{array}$ \\
Characteristic & eDiary vs eDiary \\
\hline Urgency BMs per week & 0.79 \\
BMs per week & 0.81 \\
Urgency FIEs per week & 0.62 \\
FIEs per week & 0.74
\end{tabular}

${ }^{1}$ Comparison of data from 14-day phone eDiaries from Run-In vs NOTABLe Baseline visit 